\title{
On arc efficiency in Gas Tungsten Arc Welding
}

\section{(Sobre eficiência de arco em Soldagem GTAW)}

\author{
Nils Stenbacka \\ University West, Trollhättan, Sweden. \\ nils.stenbacka@hv.se
}

\begin{abstract}
The aim of this study was to review the literature on published arc efficiency values for GTAW and, if possible, propose a narrower band. Articles between the years 1955 - 2011 have been found. Published arc efficiency values for GTAW DCEN show to lie on a wide range, between 0.36 to 0.90. Only a few studies covered DCEP - direct current electrode positive and AC current. Specific information about the reproducibility in calorimetric studies as well as in modeling and simulation studies (considering that both random and systematic errors are small) was scarce. An estimate of the average arc efficiency value for GTAW DCEN indicates that it should be about 0.77. It indicates anyway that the GTAW process with DCEN is an efficient welding method. The arc efficiency is reduced when the arc length is increased. On the other hand, there are conflicting results in the literature as to the influence of arc current and travel speed.
\end{abstract}

Keywords: Gas Tungsten Arc Welding; GTAW; TIG; Arc efficiency; Process parameters;

Resumo: O objetivo deste trabalho foi o de fazer uma revisão na literatura de valores publicados de eficiência térmica do arco do processo GTAW e, se possível, propor uma banda mais estreita de valores aceitáveis. Valores publicados para GMAW CC- mostram situar-se numa larga faixa, entre 0,36 a 0,90. Muitos poucos estudos cobrindo CC+e CA foram encontrados. Informações especificas sobre a reprodutibilidade em estudos calorimétricos tanto quanto em modelagem e simulação (considerando que tanto erros aleatórios como sistemáticos são pequenos) são escassos. Uma estimativa do valor médio da eficiência do arco indica ser este de 0,77. Isto indica, de qualquer forma, que o processo GTAW com CC-é um processo de grande eficiência. A eficiência do arco é reduzida quando o arco é alongado. Por outro lado, existem resultados conflitantes na literatura quando se estuda a influência da corrente de soldagem e velocidade de soldagem.

Palavras-Chave: GTAW, TIG, Eficiência de arco, parâmetros de soldagem

\section{Introduction}

Why is it important to know the arc efficiency at TIGwelding more precisely? GTAW is probably the largest arc welding method of all when it comes to welding stainless steels, far larger than for instance GMAW when measured by shielding gas consumption. Of great concern is to know how much of the energy is actually transferred to the material being welded. During the past years a wide range of arc efficiency values for GTAW have been reported in the standard literature, values between $0.22-0.80$ are for instance mentioned [1 - 4]. The intention of this report is to examine background references and the relevance of determined values for GTAW, and if possible to postulate a narrower band for the arc efficiency, $\eta_{\mathrm{a}}$.

Recebido em 07/10/2013, texto final em 07/10/2013.
Arc efficiency $\left(\eta_{\mathrm{q}}\right)$ (also called process efficiency, thermal efficiency or heat transfer efficiency) plays an important role in many aspects of welding technology. The concept is used for example when estimating process performance, in calculating cooling rates or cooling times, when modeling fusion characteristics etc. In order to accurately utilize modern FEM heat-flow-models it has become more important to know $\eta_{\mathrm{a}}$ more precisely, and how different process parameters (for example current, welding speed, electrode tip angle and type of shielding gas) will influence the arc efficiency.

Arc efficiency $\eta_{a}$ is normally defined as;

$\eta_{\mathrm{a}}=\mathrm{q}_{\mathrm{w}} / \mathrm{q}_{\mathrm{n}}(1)$

Where $\mathrm{q}_{\mathrm{w}}$ is the net power input $[\mathrm{J} / \mathrm{s}]$ transferred to the plate (substrate) and $\mathrm{q}_{\mathrm{n}}$ is the gross (or nominal) power input at the arc from a certain power source. The part not transferred to the work piece; $\left(1-\eta_{\mathrm{a}}\right)$, is lost through radiation, convection, electrode heating and heat conduction in the TIG torch. This schematically illustrated by Fig 1. Calorimetric methods are often used to measure $\mathrm{q}_{\mathrm{w}}$, and over the years a couple of different 
methods have been used which will be commented further on.

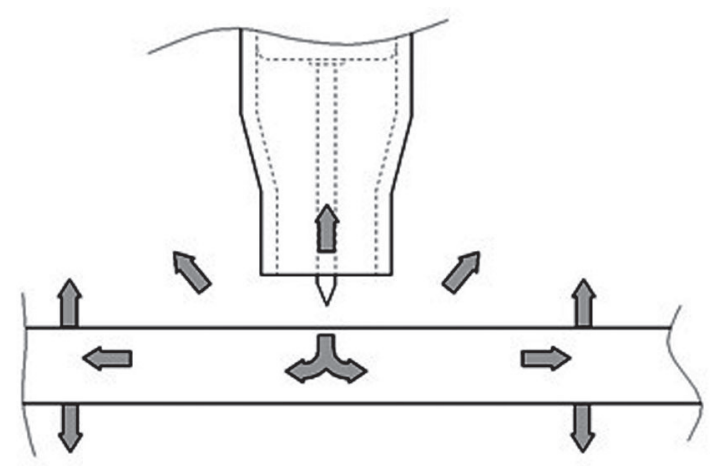

Fig 1. TIG torch and the heat transfer around it.

The gross energy input during welding can be measured in different ways. In the case of DC arc welding $\mathrm{q}_{\mathrm{n}}$ is simply the product of current $I[\mathrm{~A}]$, voltage $U[\mathrm{~V}]$ at the arc, and welding time $t$. In the case of a sinusoidal AC current, effective values of voltage $u$ and current $i$ can be used together with the power factor when estimating arc power; $P=\operatorname{uicos}(\varphi)$. A better estimate of the gross arc power, when the current and voltage are highly fluctuating for example in short arc or pulsed arc welding, is to use the arithmetic mean power value. It can be calculated from measured instantaneous current $i_{i}$ and voltage $u_{i}$ values at the arc;

$P_{a v}=\sum\left(u_{i} i_{i}\right) / n(2)$

Summation is made from $i=1$ to $i=n$. When the sampling frequency $n$ tends to high values eq. (2) is replaced by;

$P_{a v}=(1 / T) \int u(t) i(t) d t(3)$

This physically defines the average power. Integration is made over the time interval $T$ of interest [19].

Melting efficiency $\eta_{\mathrm{m}}$ (also called fusion efficiency or thermal efficiency of fusion), is another important process property. Process performance can for instance be described by the two parameters $\eta_{\mathrm{a}}$ and $\eta_{\mathrm{m}}$. The arc efficiency $\left(\eta_{\mathrm{q}}\right)$ must be known in order to experimentally determine the melting efficiency for a given process or a given set of welding parameters. Over the years it has been shown, for various processes, that only a fraction of the effective energy supplied to the substrate is actually used for melting. The remaining part is lost through heat diffusion in the base material. The ratio of the power used for melting (fusion) $\mathrm{q}_{\mathrm{m}}$ divided by the power actually supplied $\mathrm{q}_{\mathrm{w}}$ to the substrate defines the melting efficiency according to;

$\eta_{\mathrm{m}}=\mathrm{q}_{\mathrm{m}} / \mathrm{q}_{\mathrm{w}}(4)$

Analytical models for calculating $\eta_{\mathrm{m}}$ have for instance been given by [3-4]. For a rapidly moving high power heat source about $48 \%$ of the effective (net) heat input is available for fusion (2D case and no filler material). This is an analytically calculated value based on heat diffusion exclusively perpendicular to the moving heat source and without any addition of filler material [4]. Experiments support this value [14, 16, 21]. It is interesting to note that the analytical 2D model and experimental support for it was given already in 1952 by Wells [21].

With lower travel speeds, heat conduction in the moving direction of the power source will become more important and $\eta_{m}$ will consequently be lower. For slow moving power sources, like manual GTAW, the thermal efficiency will indeed be much lower. A value of about 0.16 has for instance been reported by [17] in experiments with slow moving GTAW (travel speed about $0.5 \mathrm{~m} / \mathrm{min}$ ).

\section{Methods to determine arc efficiencies}

Two basically different routes can be selected in order to determine the arc efficiency $\left(\eta_{\mathrm{a}}\right)$. One is through calorimetric experiments and the other one is through calibrating heat flow models with measured parameters (for instance depth of penetration, fused area or maximum temperature at a certain location from the weld centerline etc.). In both cases there are errors connected to the used method. Calorimetric experiments can be said to be a direct approach, whereas calculations through modeling and simulations (relaying on several fundamental assumptions inherent to the model) is an indirect way of estimating $\eta_{\mathrm{a}}$. In the past calorimetric experiments was used extensively, whereas modeling studies have increased in popularity during later years partly because of increased accuracy and speed in the calculations (for example with FEM).

Calorimetric experiments measures the net energy input $\mathrm{q}_{\mathrm{w}}$ transferred to the substrate. The following methods are for example mentioned [15].

1. Cooling water is used to remove the heat from the substrate during welding, and the efficiency is estimated from the temperature rise and flow of cooling water.

2. The workpiece is dropped into liquid nitrogen directly after welding and the weight loss of liquid nitrogen due to vaporization is measured.

3. Welding is performed on a plate placed at the bottom of a calorimeter, the electrode is withdrawn and the lid of the calorimeter is quickly closed. Total heat transfer to the workpiece is estimated by integrating the calorimetric signal over the entire cooling time.

There are of course variants of the third case [18]. One variant of the first one for, and often used in GTAW experiments, is to mount a fixed TIG torch with the arc burning against a water cooled copper anode $[6,12]$, but other anode materials has also been used [5]. Some argue that for a given arc current and voltage the heat intensity on a water cooled anode (DCEN) is greater than that on a molten weld pool, because the convective heat transport by the plasma to the anode would be greater [12]. However it has also been pointed out that about $89 \%$ of the energy transfer from an arc is by electrons [6]. Convection and radiation accounts for the remaining $11 \%$ and could be affected by a lower surface temperature. But it should not have a major effect on arc efficiency $\left(\eta_{a}\right)$, although a difference in the order of 4 to $6 \%$ has been estimated [13].

Accurate calorimetric measurements of $\eta_{a}$ are difficult, and 
unless systematic errors are accounted for this may lead to underestimate (or even overestimate) of actual values [20]. The total error in calorimetric studies depends basically on two parts;

$\Delta \eta_{\mathrm{a}} / \eta_{\mathrm{a}}=\Delta \mathrm{q}_{\mathrm{w}} / \mathrm{q}_{\mathrm{w}}+\Delta \mathrm{q}_{\mathrm{n}} / \mathrm{q}_{\mathrm{n}}(5)$

The measuring error in the gross arc power input $\Delta \mathrm{q}_{\mathrm{n}} / \mathrm{q}_{\mathrm{n}}$ depends on how arc current and voltage is measured and how the gross arc power is calculated. Electrical measuring systems have accuracy better than $1 \%$ and thus the error in $\Delta q_{n} / q_{n}$ should be less than that. Other claims error values for instance in the order of 3\% [6] or even higher like for instance 5\% [18].Accuracy and errors will be discussed later on.

The error in $\Delta \mathrm{q}_{\mathrm{w}} / \mathrm{q}_{\mathrm{w}}$ can on the other hand be much larger. There are both systematic and random errors which will influence the result. The calorimeter (design and usefulness) itself may have a large influence. Calibrations of a Seebeck Envelope Calorimeter (SEC) for instances indicates an accuracy better than $1 \%[13,14,16]$, whereas random errors for an insulated box and a nitrogen calorimeter was reported to be $1.5 \%$ and $8 \%$ respectively [20]. Further comments to the SEC system will be given below. The uncertainty when estimating the enthalpy increase in a workpiece was on the other hand reported to be about $3 \%$ in one case [18]. Thus the total error $\Delta \eta_{\mathrm{a}} / \eta_{\mathrm{a}}$ could be in the order of $10 \%$ or larger as is also discussed later. The reproducibility in repeated measurements in one case was reported to be $10 \%$ [6].

Larger errors can, however, be introduced due to uncontrolled heat losses prior to the start of the calorimetric measurements $[20,26]$. Heat losses will for instance occur during welding (from plate surface to surroundings and/or to a clamping jig used during the welding operation), when unclamping the sample, during the transfer of the sample to the calorimeter etc.

The influence of welding time and delay time on determined $\eta_{a}$ values was for instance recently investigated for GMAW [20]. Heat losses during welding and handling operations can lower determined arc efficiencies significantly (in the worst case up to $30 \%$ absolute). This has to be controlled and compensated for when determining $\eta_{\mathrm{a}}$. One way is to do this (if the measuring population is large enough) is to extrapolate down to zero welding and delay time [20].

As mentioned above, analytical and numerical methods (modeling and simulation) have also been used in estimating arc efficiency $\left(\eta_{\mathrm{f}}\right)$. It can be done in various ways, for instance by synchronizing measured maximum temperatures in the HAZ, or to correlate depth of penetration or fused area with values predicted from moving heat source solutions in the search for optimum $\eta_{a}$ value. The method can be classified as semiempirical. Different approaches have been used like analytical solutions with a point/line (Rosenthal/Rykalin solutions) heat source or distributed heat sources (Rykalin, Pavelic or Goldak), and numerical methods with finite difference or finite element $[8,13,15,17,25,27,28]$. The accuracy of matched $\eta_{a}$ values depends among other things to a high degree on heat source modeling, material data used in the computations and their temperature dependence (density, thermal conductivity, heat capacity, phase change, melting temperature, emissivity etc.), and the accuracy in measuring the matching parameter (depth, width or size fused area). It has been difficult to find reports that explicitly evaluate the $\eta_{a}$ accuracy in modeling-simulation attempts, and/or the sensitivity in the analytical/numerical model to variations in different measured input parameters.

\section{Earlier studies of GTAW arc efficiency}

In an early work, based on Russian calorimetric experiments, arc efficiency $\left(\eta_{a}\right)$ values between $0.50-0.70$ were reported by Rykalin [3] for a carbon arc, which have a similarity with a TIG arc. It is also mentioned that the arc efficiency decreases with increased arc length (increased arc voltage) due to increased heat losses [3].Results supporting these $\eta_{\mathrm{a}}$ values were published in early works during the 50 -ties and 60 -ties $[5,6]$. This will be commented more in detail in the following.

Schellhaase's [2] interesting monograph from 1985 covers several processes and quotes several references (mainly German). For GTAW and mild steel reported values varies between 0.45 to 0.75 . There is no information if this is DC- or $\mathrm{AC}$-welding. It is mentioned however that increasing arc power decreases the arc efficiency. Several heat loss mechanisms are also mentioned. With increasing arc energy losses through radiation, heat conduction and convection will increase and thereby reducing the effective arc efficiency.

Apps\& Milner [5] studied heat flow in TIG-welding without any filler material for aluminum, lead, nickel, copper and Armco iron. The majority of heat determined was due to the electron current in the arc which enters the small area of the anode spot. Another smaller heating part stems from the heat received from the positive arc column by either radiation or gaseous conduction. Heat input measurements were made as calorimetric tests. A normal commercial welding torch was used and the metal specimen was placed above a copper calorimeter. After $10-30 \mathrm{~s}$ welding time the arc was extinguished and the specimen dropped into the calorimeter. Corrections for heat losses from the calorimeter were made. It is mentioned that variations in arc time had no effect on the results, contrary to other results [20]. Direct current (DCEN) was used in all cases except for aluminum.

Measurement of current and voltage presented no difficulties with DC arcs, but with AC there were a question of current and voltage waveforms [5]. Current was almost sinusoidal and the RMS value was recorded with "normal" AC instruments. Furthermore the arc voltage was in phase and exhibited an almost square waveform (measured with an oscilloscope), the maximum value were recorded by an AC instrument. Consumed power was calculated by taking $90 \%$ of the product of the instrument readings. As will be seen later substantial errors can be introduced when using RMS values if current and voltage are fluctuating a lot for instance in pulsed GMAW [19]. Arc efficiency values based on RMS values can be substantially lower than "true" values calculated from average instantaneous power. Anyway the values determined by Apps \& Milner [5] were;

- Armco iron (DCEN) $0.60-0.78$

- $\operatorname{Nickel}(\mathrm{DCEN}) \quad 0.44-0.56$

- Aluminum (AC) $0.31-0.44$

Wilkinson and Milner [6] studied the energy distribution 
in arcs between a non-consumable (fixed) tungsten electrode and a water-cooled copper anode in different shielding gases (argon, nitrogen, helium and hydrogen). The main part of the investigation was directed to the examination of the heat flow to the anode, which comprised electron heating together with heat transfer from the plasma jet. They found that the major part of the energy expended in the arc was found to go to the anode; the remainder was divided between cathode heating and heat carried away by the gas leaving the arc region at high temperatures $\left(1000-6000^{\circ} \mathrm{K}\right)$.

The experimental set up and the measuring procedure is described in detail [6]. The authors mention that precautions were indeed necessary in order to obtain reproducible results. When the selected measuring technique was adopted, the measured heat and power consumed usually agreed within $3 \%$ or less. However, when measurements were made from one occasion to another the reproducibility was within 10\%. Quoted energy values are mean values from several experiments (usually three, but occasionally more).

The heat entering the anode accounted for $80-90 \%$ of the total energy dissipated in the arc and was about the same for the different shielding gases [6]. But it decreased with increasing arc length (from $90 \%$ down to $80 \%$ at $10 \mathrm{~mm}$ arc length). With nitrogen as shielding gas the arc efficiency was some 5-10 $\%$ higher (depending on arc length) than with argon. The heat given to the cathode was found to be about the same for both gases and amounted to only a few percent of the total energy.

In a classical work by Christensen et al.[7], $\eta_{\mathrm{a}}$ was determined for several processes like SAW, MMA, GMAW and GTWA. They used a calorimetric procedure consisting of depositing a weld bead on a plate cooled by a rapid stream of running water, the temperature rise of which was measured by means of a thermocouple. Details of their measuring technique were reported elsewhere and the test conditions are not known. The following values were, however, reported for GTAW;

\section{- Mild steel (DCEN) $0.36-0.46$ \\ - Aluminum (AC) $0.21-0.43$}

These values are much lower than TIG arc efficiencies reported by contemporary and later studies. It is interesting, however, to note their observation that $\eta_{\mathrm{a}}$ values reported by Apps \& Milner [5] were considerably higher than their own values for mild steel. The reason for the deviation was however not explored further.

An early modeling and simulation attempt was made by Niels \& Jackson [8]. Welding was made on a $25 \mathrm{~mm}$ thick steel base plate (mild steel, HY80- and HY130-steel) and they measured the temperature response at a certain location from the GTAW bead-on-plate weld fusion line. Effective (net) power input $\mathrm{P}_{\mathrm{e}}$ was calculated with the Rosenthal equation for the $3 \mathrm{D}$ case (point source, semi-infinite body, constant thermal material properties, no heat losses to the surroundings etc.), together with maximum recorded temperatures $\mathrm{T}_{\text {max }}$ at certain locations from the weld line and recorded process parameters (travel speed $\mathrm{V}$ and total arc energy $\mathrm{P}_{\mathrm{t}}$ ). Arc efficiency was then given by $\eta_{\mathrm{a}}=\mathrm{P}_{\mathrm{e}}$ / $\mathrm{P}_{\mathrm{t}}$. They calculated arc efficiency values in the range $0.35-0.65$.
They report that $\eta_{\mathrm{a}}$ was lowered from 0.65 down to 0.35 when the arc current was increased from $125 \mathrm{~A}$ to $225 \mathrm{~A}$, contrary to other results $[16,18,28]$. Changes in electrode tip vertex angle (from $30^{\circ}$ to $120^{\circ}$ ) did not influence calculated arc efficiency values.

Interesting calorimetric experiments were made by Collings et al. [23] with high speed GTAW DCEN (travel speeds between 0.1 to $1 \mathrm{~m} / \mathrm{s}$ and arc currents between 100 to $650 \mathrm{~A})$. Their apparatus included a fixed TIG torch and a rotating anode. The magnitude of the total heat transferred to the workpiece could be determined and the arc efficiency calculated. Melting efficiency under various conditions was also determined (maximum value reported was about 0.5 ). A wide range of welding conditions were studied (current, travel speed, tip angle, electrode distance and additions of $\mathrm{H}_{2}$ to the shielding gas Ar). Workpieces was either mild steel or stainless steel. It was shown that the arc efficiency for these high speed TIG arcs were in the range $0.77-0.90$, these values are similar to the $\eta_{a}$ values for TIG arcs moving at speeds at an order of magnitude less. Increased electrode distance (arc gap) lowered $\eta_{\mathrm{a}}$. Moreover, the heat input to the workpiece per unit time was virtually proportional to arc current and insensitive to large changes in electrode tip angel and travel speeds, within the observed experimental scatter of $\pm 10 \%$ [23]. Additions of $10-20 \% \mathrm{H}_{2}$ to the shielding gas increased the arc efficiency.

Ghent et al.[9] conducted calorimetric experiments with a fixed and a moving TIG-torch DCEN. They report that the arc efficiency decreases with increasing arc power. Their values can be estimated from their report to be between 0.83 to 0.58 (arc power between 1.2 to $3.0 \mathrm{~kW}$ ), i.e., for stationary or moving weld pools. It is mentioned that the efficiency can be lowered either by increasing arc gap or by increasing the current. Net power input will depend on the heat losses from the anode [9]. There is no report on measurement errors except for an information that total power collected varied between 0.97 to 1.06 of power generated. Smartt et al.[11] has shown that the GTAW arc efficiency decreases with increasing arc voltage. He reports an arc efficiency value of 0.75 for a 304 stainless steels.

Tsai \& Eagar [12] made an experimental study of heat and current fluxes, and their distribution, in GTAW with a split water cooled copper anode (fixed torch). Heat and current distribution follows each other closely, which is plausible since a major part of the heat is carried by electrons. Measurements were also made on arc efficiency and they determined values greater than 0.80 . In fact $\eta_{\mathrm{a}}$ drops slightly from 0.90 at 100 A down to 0.82 at $280 \mathrm{~A}$.

One example of the use of the Seebeck Envelope Calorimeter (SEC) is the work by Geidt et al. [13]. With the calorimeter lid open a $75 \mathrm{~mm}$ long GTA bead-on-plate weld (DCEN) was made on a $12.7 \mathrm{~mm}$ thick 304L stainless plate. In all trials travel speed was constant at $0.847 \mathrm{~mm} / \mathrm{s}$. Welding heat input varied between $0.57-2.41 \mathrm{MJ} / \mathrm{m}$. The calorimeter lid was closed over the sample immediately after completion of welding and about 6 hours was required to reach equilibrium. Determined arc efficiency values varied between 0.80 to 0.84 , with an average of $0.81 \pm 0.013$. The $95 \%$ confidence range is therefore 0.79 - 0.84. These values are high compared values determined by 
Christensen et al [7] and Niles \&Jackson [8], but supported by several calorimetric measurements and later modeling and simulation calculations, and by the early measurements by Apps \& Milner [5] and Wilkinson et al [6].

An interesting part in the study of Geidt et al [13] is that they also compared arc efficiencies determined from temperature fields and fusion zone measurements with the calorimetric values. As mentioned earlier, values thus determined are of course adjusted values to obtain agreement between analytical and/or numerical solutions and experimental measurements (in their case it was the penetration depth). The average value from calculations using a moving-point source solution (the 3D Rosenthal equation) gave an average value of $0.57 \pm$ 0.06 , which is about $30 \%$ lower than the reported calorimetric average value. They conclude that for the overall prediction of weld characteristics, for instance when calculating $\eta_{a}$, more correct models must be used; incorporating for example distributed heating, heat of fusion, thermal property variation and convection etc. When using more advanced models (like FEM models) estimated arc efficiencies values approach those $(0.75-0.80)$ obtained from calorimetric measurements [13].

\section{Reported GTAW arc efficiency values from 1990 and onwards}

Fuerschbach \& Knorovsky [14] made extensive calorimetric studies of GTAW and PAW (DCEN), with similar calorimetric equipment (SEC) as Geidt, et. al. [13] used in their study. Edge welds were chosen (industrial application was in fact microwelded components). The experimental set up for GTAW (DCEN, continuous and pulsed current) was extensive. Two different base materials were included (304L SS and Nickel $200)$ and two test plates (1.3 $\times 25 \times 127 \mathrm{~mm}$ each), were joined together with an edge weld. Arc output energy was determined by multiplying the voltage and current waveform together, and integrating the resulting power waveform for the weld period using the measuring oscilloscope's internal software. Travel speed varied between $4.2-25.4 \mathrm{~mm} / \mathrm{s}$, current between $29-205$ A, pulse duty cycle between $0.2-1.0$ and pulse rate between $8.3-27.8 \mathrm{~Hz}$, with differences whether there were continuous or pulsed current experiments.

Anyway, their results indicates that arc efficiency were relatively insensitive to travel speed. It was mostly around 0.8 -0.85 for travel speeds between $10-25 \mathrm{~mm} / \mathrm{s}$. But decreased slightly from 0.8 to 0.7 when travel speed was reduced from 10 to $5 \mathrm{~mm} / \mathrm{s}$. Since the major part of the energy transfer is by electrons (ca 90\%), the current is of course the dominate parameter in the arc energy balance, and thus convective and radiative losses will be of secondary importance. The arc efficiency was also relatively insensitive to duty cycle in the pulsed current experiments and $\eta_{\mathrm{a}}$ values were between $0.80-$ 0.85 , with a slight reduction down to about 0.75 for the lowest duty cycle (ca 0.28 ). Another interesting result was the lack of arc efficiency dependence on anode material (304L or Ni200). It might indicate that the electron work functions in a GTAW arc for the two materials are similar, since the anode work function is believed to strongly affect the GTAW arc efficiency [14].
Dutta et al. [15] determined gas tungsten arc efficiencies through a combined experimental analytical (computational) technique. Measurements of width and depth of weld pool were obtained from sections using optical microscopy. Based on these measurements a 3D FEM model was used to calculate the arc efficiency, which accounted for weld pool convection and variations in specific heat. Welding was done in a groove (depth $\mathrm{x}$ width: $1.6 \times 1.6 \mathrm{~mm}$ ) in order to simulate butt welding, but also as bead-on-plate welds as a comparison. In all test a naval HY-80 steel $(0.16 \% \mathrm{C})$ was used. Welding speed varied between $1.27-2.12 \mathrm{~mm} / \mathrm{s}$, current between $237-322 \mathrm{~A}$ and arc voltage between $10.7-13.8 \mathrm{~V}$. Their calculations revealed a mean value of about $72 \%$ for the arc efficiency. Reported variations (between $0.62-0.85$ ) were claimed to be due to variations in arc current, voltage, welding speed and inherent unsteadiness of the welding process itself. Dutta et al. [15] also mentioned that a higher power input results in lower arc efficiencies and that the slower the speed the lower the efficiency. They also noted no significant difference in arc efficiency between grooved and ungrooved plates, at comparable welding speed and power input.

Another example of the use of the SEC equipment is the study of DuPont \& Marder [16]. They made an extensive experimental study on arc efficiencies for several processes like PAW, GTAW, GMAW and SAW. GTA welding was done on a $100 \times 100$ $\mathrm{mm}$ square plate, $25 \mathrm{~mm}$ thick, steel plate (A 36 carbon steel). Current varied between $250-350 \mathrm{~A}$, voltage between $15-16 \mathrm{~V}$, whereas travel speed was kept constant at $7 \mathrm{~mm} / \mathrm{s}$. Welding time was kept below $10 \mathrm{~s}$ and transfer time to the calorimeter below $3 \mathrm{~s}$, in order to minimize heat losses before the substrate was in the calorimeter. They also made a calculation of heat losses prior to measurements (welding + transfer), and concluded that they were less than $1 \%$ of total arc power and could therefore be neglected. The arc efficiency did not vary significantly over the current range investigated and a value of $\eta_{\mathrm{a}}=0.67 \pm 0.05(8 \%$ variance) was determined for GTAW DCEN.

The thermal response of spheroidal graphite cast iron (substrate) was studied in calorimetric experiments by Orlowicz \& Trytek [24] in GTAW DCEN. Travel speeds ranged from 0.2 to $0.8 \mathrm{~m} / \mathrm{min}$ and arc currents from 100 to $300 \mathrm{~A}$. The influence of different electrode distances (arc gap from 3 to $6 \mathrm{~mm}$ ) on $\eta_{\mathrm{a}}$ was also studied. They determined arc efficiency values between $0.39-0.77$ and concluded that $\eta_{a}$ was strongly dependent on travel speed (decreased with increased travel speed), contrary to what was reported earlier. At low travel speeds $(<0.4 \mathrm{~m} / \mathrm{min}$ and currents between 100 to $300 \mathrm{~A}$ ) they report $\eta_{\mathrm{a}}$ values in the range $0.66-0.77$, i.e. similar values as reported earlier. The range 0.66 -0.77 is the more plausible arc efficiency range. Increased arc gap reduced the arc efficiency [24].

Mishra \& DebRoy [25] used a heat-transfer and fluid-flowbased model to obtain a specific weld geometry using various combinations of welding variables. They point out that the models for GTAW have five "uncertain parameters", i.e., arc efficiency, arc radius, power distribution factor, and the effective thermal conductivity and viscosity of the liquid metal. The numerical model was applied to GTAW DCEN of Ti-6Al-4V alloy to calculate various sets of welding variables to achieve specified weld geometries. The optimized value of the arc 
efficiency was calculated to 0.72 , in line with what was reported earlier.

When it comes to calorimetric measurements Malin \& Sciammarella [26] makes some interesting statements about measurement errors when using the SEC equipment, and specific drawbacks when applied in welding. They point out for instance that the SEC is not a turnkey device intended for welding. In fact it was designed for biomedical research and needs additional equipment (like a chiller, a data-acquisition unit, processing hardware etc) and modifications to function properly in welding experiments. It also requires about $6 \mathrm{~h}$ to make one measurement. Anyway, the errors introduced when applying the SEC was estimated in the following manner. The SEC does not account for heat losses during welding and transfer of the specimen into the calorimeter. These losses depend on a number of factors (size of specimen and its physical properties, welding and transfer time etc.). The heat thus neglected could cause a measurement error in the order up of $2 \%$ [26]. Moreover, the SEC does not differentiate between transient and quasistationary energies, because the specimen has a rather short length (max $90 \mathrm{~mm}$ ), and therefore the transient zones (start and stop areas) will influence the measurements. An additional source of error up to $7 \%$ will then be introduced since transient and stationary (nominal) energies will be averaged [26]. Thus the total measuring error of $\eta_{\mathrm{a}}$ could be in the order of $9 \%$.

Recently Gonzalez et al. [27] studied experimentally the heat flux transferred to a fixed anode (stationary water cooled copper anode). Although their main object was to determine transferred heat flux (for instance temperatures and temperature profiles), some interesting data can be found in their paper when it comes to power transmitted to the cooling water and total (input) power, and the scatter in these measurements. The average arc efficiency for four different input powers (from 1.1 to $1.6 \mathrm{~kW}$ ) was 0.70 , range between 0.63 to 0.77 . The scatter in their power input measurements (estimated) was $< \pm 2 \%$, whereas the scatter in the power transmitted to the cooling water (estimated) was $\pm 10 \%$.

Goncalves et al. [17] compared two modeling techniques when studying thermal phenomena (heat flux) during GTAW. The first thermal model (A) considers quasi-stationary heat conduction (basically Rosenthal) in the interior of a plate, whereas the second one (B) uses a general transient heat equation for heat diffusion with phase change. In both cases the heat flux generated from the welding process could be estimated and temperature curves/profiles calculated considering phase change, varying thermal properties and heat losses to the surroundings due to convection and radiation. Calculated temperature profiles (using the two models) were compared with experimental ones obtained in TIG welding an AISI 304 steel plate with dimensions $200 \times 50 \times 4 \mathrm{~mm}$, current $78 \mathrm{~A}$, voltage $15 \mathrm{~V}$ and a constant travel speed of $8.33 \mathrm{~mm} / \mathrm{s}(\mathrm{P}=1.178 \mathrm{~kW})$. Based on heat flow estimations the arc efficiency was calculated with model A to be $0.67 \pm 0.09$ (varied between $0.56-0.77$ at four different thermocouple locations). The accuracy of model B was tested by calculating the weld pool radius and with measured values (golden sections) of the radius. The relative error was $4 \pm$ $2.0 \%$ (four locations) with maximum error $<7 \%$.

Model B was used in estimating; heat of fusion, heat transfer in the plate and heat losses due to convection/radiation. Goncalves et al. [14] could then estimate arc efficiency and thermal efficiency dynamically during the whole welding sequence through synchronization with the thermocouples. The thermal (fusion) efficiency was constant during the welding operation and had a value of about 0.16 in their specific case. The "instantaneous" arc efficiency was about 0.8 (during $2 \mathrm{sec}$ arc start), but fell slightly in an asymptotic manner from about 0.74 (after completion of arc start) down to about 0.70 at the end of the welding operation, i.e. when more heat is consumed during heat transfer in the plate and heat losses due to convection/ radiation.

Several different process situations were studied by Cantin $\&$ Francis[18]. The influence of polarity, alternating current balance, shielding gas composition ( $\mathrm{Ar}, \mathrm{Ar}+75 \% \mathrm{He}, \mathrm{He}$ ), arc length and welding current on arc power and arc efficiency were investigated. They used a calorimetric approach which comprised experiments in which GTAW weld runs were made on a cubical $(110 \times 120 \times 120 \mathrm{~mm})$ insulated block of electrical conductor grade aluminum. The temperature rise in the block was measured with several thermocouples attached to it and the energy absorbed in the sample was then calculated. Arc power was estimated by numerical integration of $u(t) i(t)$ during welding time $T$. As one of the few, Cantin \& Francis [18] also discussed the significance of different errors in their measurements and came to the assumption that the uncertainty when estimating arc power would be about $5 \%$, whereas the uncertainty when estimating the enthalpy in the workpiece would be about 3\%. Total error in arc efficiency measurements was then about $8 \%$.

The arc efficiencies determined in DCEN experiments fell within the range $0.76-0.89$, i.e. in the same range as the calorimetric experiments mentioned earlier for different materials and much higher than the values reported by Christensen et al. [7]. The major part of the arc power is transferred to the workpiece and relative high arc efficiencies were obtained. Their results also showed that the type of shielding gas had a significant influence on the arc efficiency in DCEN tests. Higher $\eta_{\mathrm{a}}$ values were recorded with $\mathrm{Ar}+75 \% \mathrm{He}$ and $\mathrm{He}$ (average 0.87), than with pure Argon(average 0.79). This was explained by differences in heat losses. With Ar as shielding gas heat losses through radiation will be dominant, whereas with Helium, conduction and convection losses will dominate. Minimum in the sum of radioactive conductive and convective losses occurs with a shielding gas with $\mathrm{Ar}+75 \% \mathrm{He}$ [18]. Determined $\eta_{\mathrm{a}}$-data suggested also that changes in welding current $(100 \mathrm{~A}-200 \mathrm{~A})$ didn't have any significant influence.

As expected lower arc efficiencies were recorded with DCEP (direct current electrode positive) since the electrons condense on the electrode, and a large amount of the energy (roughly 25\%) is transferred to the electrode. On average about $25 \%$ less energy is transferred then to the workpiece in this case, compared to the previous one. Measured arc efficiencies were in the range $0.52-0.63$, but the cathode (substrate) was however the major recipient of the arc energy since $\eta_{\mathrm{a}}$ were $>0.50$. Also in this case higher $\eta_{a}$ values were recorded (average 0.62 ) with Ar $+75 \% \mathrm{He}$ compared with pure Argon (average 0.55), although the differences were not so significant as with DCEN. It was 
also found that an increase in arc length (from 2 to $4 \mathrm{~mm}$ ) gave a slight decrease in arc efficiency.

Arc efficiencies with $\mathbf{A C}$ power were intermediate of those for DCEN and DCEP and ranged between $0.65-0.83$ and were dependent on the EN (electrode negative) fraction $(0.50$ - 0.75). For Argon with EN 50\% the arc efficiency was $0.71 \pm$ 0.03 . An interesting approach in their study is the calculation of arc efficiencies at AC power by using weighted average of the arc efficiencies obtained at DCEN and DCEP polarity, under otherwise identical welding conditions. Estimated and measured arc efficiencies compared reasonably well.

Another recent example of a modeling and simulation approach is the one done by Bag \& De [27]. They mention the same uncertain input parameters as Mishra \& DebRoy [25], i.e., the data which are necessary for adequate modeling of heat transfer and fluid calculations in GTAW. But Bag \& De [27] synchronized their calculations with another substrate (stainless 304), which was TIG welded DCEN (arc power between 1.0 to $2.0 \mathrm{~kW}$ and travel speed between 5.0 to $8.8 \mathrm{~mm} / \mathrm{s}$ ). The size of the test plates is not mentioned. Calculations of the Uncertain Model Input Parameters gave an optimum arc efficiency value of 0.65 , which is somewhat below the values reported earlier.

A creative modeling approach was made by Arul \& Sellamuthu [28] recently, with the goal to overcome the difficulties in solving complex heat and fluid flow models when predicting temperature distributions, cooling rates and weld pool geometry. In their case the arc parameter, as the measure of the arc heat distribution, required for the simulation were experimentally determined from arc images. As a substrate they used 1005 carbon steel with the dimensions $150 \times 50 \times 25 \mathrm{~mm}$, current values were between 100 to $200 \mathrm{~A}$ and travel speeds between 0 to $10 \mathrm{~mm} / \mathrm{s}$. The arc images were recorded with a CCD camera. As synchronizing parameter they selected the weld pool width. They determined an average arc efficiency value of 0.74 . The scatter in their data was estimated to be in the order \pm 0.05 , when the current and travel speed varied. However, they conclude that the arc efficiency was independent of both current and travel speed. The heat distribution parameter was a function of current and independent of travel speed [28].

\section{Discussion}

Reviewed references show a wide variation in determined arc efficiency values, regardless if they were determined through calorimetric experiments or achieved by modeling and simulation studies. A summary of referred $\eta_{a}$ values and their range can be found in Table 1 .

An interesting observation is that many references have not made a thorough estimate of experimental errors in their calorimetric experiments and/or in their modeling and simulation studies. Measurement system errors, for instance, can be classified into two main categories: accuracy and precision. Accuracy is the difference between measured and actual value. This is of course difficult to estimate in the present case since the actual value is in fact unknown. Precision, on the other hand, is the variation when measurements are repeated with the same equipment. Furthermore precision has two parts, repeatability which is the variation due to the measuring equipment (the device) and reproducibility which is the variation due to the measuring system, i.e., when different "operators" measure the same object using the same equipment (device) or when measurements are made in different laboratories with the same equipment. Good repeatability means that random errors have a small influence on the result, and good reproducibility indicates that both random and systematic errors are small.

Only in a limited number of cases were the experimental errors estimated and/or discussed, moreover no clear distinction was made between accuracy and precision. In some cases precision was mentioned and it was mainly made towards repeatability (but mixed with reproducibility). Anyway, there are some reports about errors encountered in the calorimetric studies mentioned earlier. Considering these reports, the error in power input measurements should be less than $\pm 2 \%$. Whereas, several reports indicates that the error in estimating the transmitted power (or heat) to a given substrate is in the order of $\pm 10 \%$. Thus the total error could be about $\pm 12 \%$, which is the linearized error estimate according to eq. (5). This magnitude in experimental error in $\Delta \eta_{\mathrm{A}} / \eta_{\mathrm{q}}$ can to a certain degree explain the deviations between arc efficiency values given in Table 1.

A difference between two average $\eta_{a}$ values, less than $12 \%$ is not significant on a confidence level of $90 \%$ (estimated from the average value given below). If a $10 \%$ difference between two measured $\eta_{a}$ values should be significant ( $95 \%$ confidence level), it would mean that the total error in calorimetric experiments have to $< \pm 5 \%$. It is an open question if this reproducibility can be achieved with the systems used today.

Modeling and simulation experiments are also influenced by different types of errors. They can be split between errors inherent to the used model and experimental errors. The approach depends for example on several fundamental assumptions about different material parameters (e.g. specific heat, density, conductivity, viscosity etc.) and their temperature dependence, which can be more or less well known. Furthermore, in this approach there are also measurement errors, for instance when determining the synchronizing parameter (e.g. depth of penetration, width of weld bead, weld metal area or peak temperature etc.). No information was found about experimental errors in the modeling and simulation studies.

From the data given in Table 1 a possible average value and standard deviation can be estimated for GTAW DCEN. Considering the range in the individual cases, median values and individual spans are shown in Table 2. Using values in Table 2, relative and cumulative frequencies can be calculated. Assuming that all values can be described by a normal distribution, mean value and standard distribution can be estimated. Besides this assumption, it is also assumed that the substrate have no influence on the arc efficiency. This has a support in the reviewed literature mentioned earlier.

Other factors such as arc gap and power can also influence the $\eta_{a}$ value, but presently it is difficult to consider these parameters and they will be commented later.

Table 1. Summary of arc efficiency values published between 
1955 and 2011 and their range. In some cases the range was estimated from published values. The more plausible data range in [24] was selected.

\begin{tabular}{|l|l|l|l|l|}
\hline Reference & Year & $\eta_{\mathrm{a}}$ range & Substrate & Comments \\
\hline Apps \& Milner [5] & 1955 & $0.60-0.78$ & Armco iron & DCEN \\
\hline “ & “ & $0.31-0.44$ & Aluminium & AC current \\
\hline Wilkinson \& Milner [6] & 1960 & $0.80-0.90$ & Water cooled copper anode & Water cooled copper anode \\
\hline Christensen et al. [7] & 1965 & $0.36-0.46$ & Mild steel & DCEN \\
\hline “ & “ & $0.21-0.43$ & Aluminium & AC current \\
\hline Niels \& Jackson [8] & 1975 & $0.35-0.65$ & Steel & Modelling \\
\hline Ghent et al. [9] & 1979 & $0.58-0.83$ & Steel & DCEN \\
\hline Collings et al. [23] & 1979 & $0.77-0.90$ & Mild steel \& Stainless & DCEN \\
\hline Smartt et al. [11] & 1985 & 0.75 & Stainless 304L & DCEN \\
\hline Tsai \& Eagar [12] & 1985 & $0.80-0.90$ & Water cooled copper anode & DCEN \\
\hline Geidt et al. [13] & 1989 & $0.79-0.84$ & Stainless 304L & DCEN \\
\hline “ “ & “ & 0.57 & Modelling \\
\hline Fuerschbach \& Knorovsky [14] & 1991 & $0.80-0.85$ & Stainless 304L \& Ni 200 & DCEN \\
\hline Dutta et al. [15] & 1994 & $0.62-0.85$ & HY-80 steel & Modelling \\
\hline DuPont \& Marder [16] & 1995 & $0.62-0.72$ & A 36 steel & DCEN \\
\hline Orlowicz \& Trytek [24] & 2003 & $0.66-0.77(0.39-0.77)$ & Spheroidal cast iron & DCEN \\
\hline Mishra \& DebRoy [25] & 2005 & 0.72 & Ti-6Al-4V & Modelling \\
\hline Goncalves et al. [17] & 2006 & $0.56-0.77$ & Stainless 304L & Modelling \\
\hline Cantin \& Francis [18] & 2005 & $0.76-0.89$ & Aluminium & DCEN \\
\hline Cantin \& Francis [18] & 2005 & $0.52-0.63$ & Aluminium & DCEP \\
\hline Cantin \& Francis [18] & 2005 & $0.65-0.83$ & Aluminium & AC current \\
\hline Gonzales et al. [27] & 2007 & $0.63-0.77$ & Water cooled copper anode & DCEN \\
\hline Bag \& De [28] & 2010 & 0.65 & Stainless 304 & Modelling \\
\hline Arul \& Sellamuthu [29] & 2011 & 0.74 & 1005 steel & Modelling \\
\hline
\end{tabular}

Table 2. Arc efficiency range, median values and span for GTAW DCEN according to Table1.

\begin{tabular}{|l|l|l|l|l|}
\hline References & Range & Substrate & Median & Span \\
\hline$[5]$ & $0.60-0.78$ & Armco iron & 0.69 & 0.18 \\
\hline$[6]$ & $0.80-0.90$ & Copper anode & 0.85 & 0.10 \\
\hline$[7]$ & $0.36-0.46$ & Mild steel & 0.41 & 0.10 \\
\hline$[9]$ & $0.58-0.83$ & Steel & 0.71 & 0.25 \\
\hline$[23]$ & $0.77-0.90$ & Mild steel \& Stainless & 0.84 & 0.13 \\
\hline$[12]$ & $0.80-0.90$ & Copper anode & 0.85 & 0.10 \\
\hline$[13]$ & $0.79-0.84$ & Stainless 304L & 0.82 & 0.05 \\
\hline$[14]$ & $0.80-0.85$ & Stainless \& Ni 200 & 0.83 & 0.05 \\
\hline$[16]$ & $0.62-0.72$ & A 36 steel & 0.67 & 0.10 \\
\hline$[24]$ & $0.66-0.77(0.39-0.77)$ & Spheroidal cast iron & 0.72 & 0.11 \\
\hline$[18]$ & $0.76-0.89$ & Aluminum & 0.83 & 0.13 \\
\hline$[27]$ & $0.63-0.77$ & Copper anode & 0.70 & 0.14 \\
\hline
\end{tabular}


A further question which arises is whether the values given by [7] are outliners or not? With a linear regression fit to the cumulative frequency data the regression coefficient was 0.90 with all values present, and when values according to [7] was omitted the coefficient rose to 0.96 . Values in Table 2 have probably a normal distribution. Based on the whole population it can be evaluated if the upper value of 0.46 according to [7] belongs to the population or not. With Student's t-test it can be shown that this upper value it is not a part of the population (on the 0.01 level), which means that the values according to [7] are most likely outliners. When the data according to [7] were omitted the average $\eta_{\text {value is }} 0.77 \pm 0.07$ ( $10 \%$ variance). The $95 \%$ probability range is fairly large $(0.63-0.91)$ and it covers $86 \%$ of all observed values. It indicates that the GTAW process is an efficient welding method.

Figure 2 and 3 shows median values as functions of publication year, and it is interesting to note the gradual increase in calculated $\eta_{1}$ values in Fig 3 from modeling and simulation studies of the years, i.e. when the model accuracy is enhanced. The gap between the two approaches is reduced over the years.

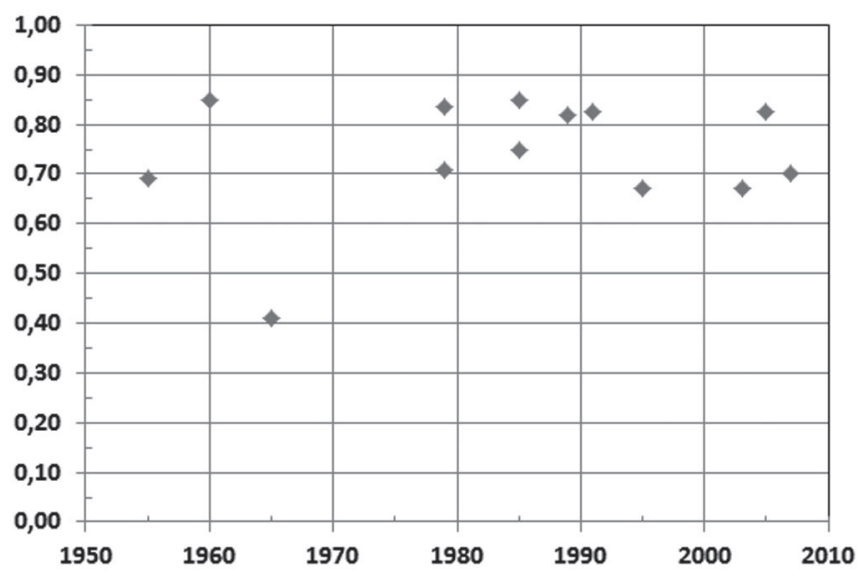

Fig 2. Published arc efficiency median values for GTAW DCEN obtained from calorimetric experiments as function of publication year. See also Table 1 and 2 .

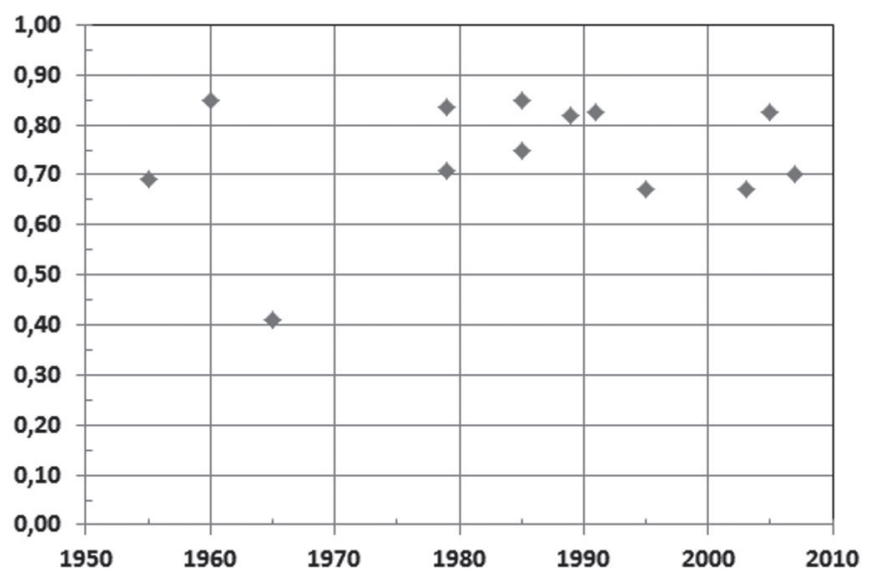

Fig 3. Published arc efficiency median values for GTAW DCEN obtained from modeling and simulation studies as function of publication year. See also Table 1 and 2 .
The majority of studies on arc efficiency so far were concerned with DCEN, although DCEP and AC current (for instance pulsed current with EN polarity) are also of industrial importance. Anyway, published data in this area indicates that $\eta_{a}$ is lower in these cases, but since there are only a limited number of published studies it is difficult to point out any specific range. Table 1 provides however some guideline.

Another interesting observation is the lack of factorial experiments or any design of experiment approach (DOE). Main process parameters of interest are for instance; travel speed, arc current and arc gap. A simple $2^{3}$ factorial test would suffice to show both the influence and the connection between these variables. There is however several articles which indicate that the arc efficiency is reduced when the arc length is increased $[3,9,23]$. But there are conflicting results with respect to the influence of arc current and travel speed. There are some reports that there is no influence of arc current or travel speed [14, 16, $18,23,28]$, whereas some claim that there is $[2,8,9,11,12,15$, 24].

\section{Conclusions}

Published arc efficiency values for GTAW show a wide range. Values between 0.36 to 0.90 have been found in the reviewed literature for GTAW DCEN. The majority of published studies were made on DCEN and only a few studies covered DCEP and AC current.

In many cases measurement errors are not reported for the applied methods. This was evident both in calorimetric experiments as well as in modeling and simulation studies. Specific information about the reproducibility in calorimetric studies (considering both random and systematic errors) was scarce. When considering several reports, the total error when determining arc efficiency with calorimetric methods was estimated to be about $\pm 12 \%$ for a "good practice" procedure. But there can be larger errors.

If a $10 \%$ difference between two measured $\eta_{a}$ values should be significant (95\% confidence level), it would mean that the total error in calorimetric experiments have to $< \pm 5 \%$. It is an open question if this reproducibility can be achieved with the systems used today.

An estimate of the average arc efficiency value for GTAW DCEN indicates that it should be about $0.77 \pm 0.07(10 \%$ variance), regardless of substrate (mild steel, stainless steel, $\mathrm{Ni}$ alloys, cast iron). One outliner value was found in the literature and it was omitted from this estimate. The $95 \%$ probability range of observed arc efficiency values is fairly large $(0.63-0.91)$. It covers $86 \%$ of the observed min-max values. It indicates anyway that the GTAW process with DCEN is an efficient welding method.

The arc efficiency is reduced when the arc length is increased. On the other hand there are conflicting results in the literature as to the influence of arc current and travel speed.

\section{Acknowledgments}

Financial support for the study given by the KK-foundation 
is gratefully acknowledged. I am also grateful to constructive comments on the manuscript made by my colleagues Dr. Isabelle Choquet and Dr. Fredrik Sikström at University West.

\section{References}

1. LANCASTER, J. F. (ed). The Physics of Welding. Pergamon Press, 1984.

2. SCHELLHASE, M., Der Schweisslichtbogen ein technologisches Werkzeug. VEB Verlag Technick (DVS), Berlin, 1985.

3. RYKALIN, Berechnung Der Wärmevorgänge Beim Schweissen. VEB Verlag Technik, Berlin, 1957.

4. RADAj D., Heat Effects of Welding. Springer-Verlag, 1992.

5. APPS, R.L. \& MILNER, D.R., Heat flow in argon-arc welding. British Welding Journal, 1955, 2 (10), pp. 475-485.

6. WILKINSON, J.B. \& MILNEr, D.R., Heat transfer from arcs. British Welding Journal, 1960, 7 (2), pp. 115-128,

7. CHRISTENSEN, N., de DAVIEs, L. V., GJERMUNDSEN, D., Distribution of Temperatures in Arc Welding. British Welding Journal, 1965, 12 (12), pp. 54 - 75.

8. NILES, R-W. \& JACKSON, C.E., Weld thermal efficiency of the GTAW process. Welding Journal 1975, 54 (1), pp. $26 s-32 s$

9. Ghent, H.W., ROBERTS, D.W., HERMANCE, C.E., KERR, H.W. \& STRONG, A.B., Arc efficiencies in TIG welds. Conf. Proc., Arc physics and weld pool behavior. The Welding Institute 1979.

10. EAGAR, T. W. \& TSAI, N. S., Temperature fields produced by traveling distributed heat sources. Welding Journal Research Supplement, December 1983, pp. 346-355.

11. SMARTT, H.B., STEWART, J.A. \& EINERSON, C.J., Heat transfer in gas tungsten arc welding. ASM Metals/Materials Technology Series, No. 8511-011, 1 - 14, ASM Int'1, Metals Park, Ohio.

12. TSAI, N. S. \& EAGER, T. W., Distribution of the Heat and Current Fluxes in Gas Tungsten Arcs. Metallurgical Transactions, Vol 16B, December 1985, pp 841 - 846.

13. GIEDT, W. H., TALLERICO, L. N. \&FUERSCHBACH, P. W., GTA Welding Efficiency: Calorimetric and Temperature Field Measurements. Welding Journal Research Supplement, January 1989 , pp. $28 \mathrm{~s}-32 \mathrm{~s}$.

14. FUERSCHBACH, P. W. \&KNOROVSKY, G. A., A Study of Melting Efficiency in Plasma Arc and Gas Tungsten Arc Welding. Welding Journal, Research Supplement ,Nov $1991,287 \mathrm{~s}-297 \mathrm{~s}$.
15. DUTTA, P., JOSHI, Y. \&FRANCHE, C., Determination of gas tungsten arc welding efficiencies. Experimental Thermal and Fluid Science, Vol 1, Issue 1, July 1994, pp. 80-89.

16. DUPONT, J.N. \&MARDER, A.R., Thermal Efficiency of Arc Welding Processes, Welding Journal, Research Supplement, Dec 1995, 406s - 416s.

17. GONCALVES, C. V., VILARINHO, L. O., SCOTTI, A. \&GUIMARAES, G., Estimation of heat source and thermal efficiency in GTAW process by using inverse techniques. Journal of Materials Processing Technology 172 (2006), pp. $42-51$.

18. CANTIN, G.M.D. \& FRANCIS, J.A., Arc power and efficiency in gas tungsten arc welding of aluminium. Science and Technology of Welding and Joining, 2005, 10, 200-210.

19. JOSEPH, A., HARWIG, D., FARSON, D.F. \&RICHARDSON, R., Measurement and calculation of arc power and heat transfer efficiency in pulsed gas metal arc welding. Science and Technology of Welding and Joining, 2003, 8, 400-406.

20. N. PÉPE, S. EGERLAND, P.A. COLEGROVE, D.YAPP, A. LEONHARTSBERGER, A. SCOTTI, Measuring the process efficiency of controlled gas metal arc welding processes, Science and Technology of Welding\& Joining, Volume 16, Number 5, July 2011 , Pages 412-417.

21. HIRAOKA, K., SAKUMA, N. \& ZIJP, J., Energy balance in argon-helium mixed gas tungsten (TIG) arcs. Welding International, 199812 (5), pp. 372 - 379.

22. WELLS, A.A., Heat flow in welding. Welding Journal, May 1952, pp. 263s - 267s.

23. COLLINGS, N., WONG, K.Y. \& GUILE, A.E., Efficiency of tungsten-inert-gas arcs in very-high-speed welding. Proc. IEE, Vol. 126, No. 3, March 1979, pp. 276 - 280.

24. ORLOWICZ, A.W. \& TRYTEK, A., Susceptibility of Iron Castings to Heat Absorption from an Electric Arc and to Hardened-Layer Shaping. Metall. \& Material Trans. A, Vol 34A, Dec 2003, pp. 2973 - 2984.

25. MISHRA, S. \& DEBROY, T., A heat-transfer and fluidflow-based model to obtain a specific weld geometry using various combinations of welding variables. J. Appl. Phys. 98, 2005, 044902.

26. MALIN, V. \& SCIAMMARELLA, F., Controlling Heat Input by Measuring Net Power. Welding Journal, July 2006, pp. $44-50$.

27. GONZALEZ, J.J., FRETON, P. \& MASQUERE, M., Experimental quantification in thermal plasma medium of the heat flux transferred to an anode material. J. Phys. D: Appl. Phys. 40 (2007) 5602-5611. 
28. BAG, S. \& DE, A., Probing Reliability of Transport Phenomena Based Heat Transfer and Fluid Flow Analysis in Autogeneous Fusion Welding Process. Metall. \& Material Transactions A, Vol 41A, Sep. 2010, pp. 2337-2347.

29. ARUL, S. \& SELlAMUTHU, R., Application of a simplified simulation method to the determination of arc efficiency of gas tungsten arc welding (GTAW) and experimental validation. Int. J. Computational Material Science and Surface Engineering, Vol. 4, No. 3, 2011, pp. $265-280$. 